\title{
Response to treatment with intra-articular triamcinolone hexacetonide and triamcinolone acetonide in oligo articular juvenile idiopathic arthritis
}

Rana Harhay ${ }^{1 *}$ (D) Wajiha Jeelani², Barbine Tchamba Agbor Agbor ${ }^{3}$, Teresa Hennon², Brian H. Wrotniak ${ }^{1}$ and Rabheh Abdul-Aziz ${ }^{2}$

\begin{abstract}
Background: Oligo-articular juvenile idiopathic arthritis (Oligo JIA) is the most common subtype of juvenile idiopathic arthritis. Intra-articular corticosteroid (IAC) injection is a mainstay treatment of oligo JIA providing pain relief, improving mobility and preventing further joint destruction in the majority of patients. In 2015, production of triamcinolone hexacetonide $(\mathrm{TH})$ an intra-articular corticosteroid was discontinued in the United States leading to use of triamcinolone acetonide (TA) as an alternative. In this study, we compared response to treatment in children with oligo JIA who underwent therapy with intra-articular TA and TH injection.
\end{abstract}

Methods: Our study is a retrospective chart review of children with oligo JIA who were treated with IAC injections with TH between January 2012 and June 2015 and TA between J uly 2015 and December 2018. The two groups were followed at John R. Oishei Children's Hospital of Buffalo and were evaluated for response to treatment, side effects and predictors of response including duration of disease before treatment, erythrocyte sedimentation rate $(E S R)$, and c-reactive protein (CRP). Response to treatment was defined as at least 6 months follow up without evidence of active arthritis in injected joints. Patients were considered to be non-responders if they continued to show active arthritis during their first follow up after joint injection. The primary objective was to evaluate whether there was a significant difference in rate of response between TH and TA.

Results: Forty-nine patients, 38 female and 11 male with oligo JIA were included in the study. The average age was 6.7 years. A total of 111 joints were injected includin g 78 knees, 13 ankles, 9 wrists, 4 hips, 4 elbows, 2 TMJ and one subtalar joint. In the TA group, 49\% (29/59) did not show response to injection compared to $27 \%(14 / 52)$ in the TH group. After 6 months, response rates were better for individuals injected with TH compared to TA (73\% vs. 51\%). In general, response to intra-articular TH was superior to TA with $P=.016$ using chi-square test of independence. This difference in outcome was not influenced by other variables such as duration of illness before treatment ( $P$ value 0.784) or elevated ESR and CRP. No difference in side effects between the two groups were noted.

(Continued on next page)

* Correspondence: rmasoud@buffalo.edu

'Department of Pediatrics, University at Buffalo, Oishei Children's Hospital, Buffalo, NY, USA

Full list of author information is available at the end of the article

(c) The Author(s). 2021 Open Access This article is licensed under a Creative Commons Attribution 4.0 International License, which permits use, sharing, adaptation, distribution and reproduction in any medium or format, as long as you give appropriate credit to the original author(s) and the source, provide a link to the Creative Commons licence, and indicate if changes were made. The images or other third party material in this article are included in the article's Creative Commons licence, unless indicated otherwise in a credit line to the material. If material is not included in the article's Creative Commons licence and your intended use is not permitted by statutory regulation or exceeds the permitted use, you will need to obtain permission directly from the copyright holder. To view a copy of this licence, visit http://creativecommons.org/licenses/by/4.0/. The Creative Commons Public Domain Dedication waiver (http://creativecommons.org/publicdomain/zero/1.0/) applies to the data made available in this article, unless otherwise stated in a credit line to the data. 
(Continued from previous page)

Conclusion: Our results in conjunction with prior published data suggests that $\mathrm{TH}$ intra-articular joint injection in oligo JIA is superior to TA, although future controlled trials are necessary for confirmation. An effective, long lasting treatment can have a great impact on the outcome of these children.

Keywords: Oligo-articular juvenile idiopathic arthritis (Oligo JIA), Intra-articular corticosteroid (IAC), Triamcinolone hexacetonide $(\mathrm{TH})$, Triamcinolone acetonide (TA)

\section{Background}

As defined by the International League of Associations for Rheumatology (ILAR), juvenile idiopathic arthritis (JIA) is arthritis that occurs before the age of sixteen and lasts for at least 6 weeks [1]. Oligo JIA is the most common subgroup of JIA, accounting for at least $40 \%$ of all cases of the disease [2]. Oligo JIA is an insidious disease with asymmetric involvement of 1 to 4 joints, most commonly in the lower limbs. Symptoms can persist into adulthood leading to permanent damage of joints, contractures, and physical disability [3]. In 2011, guidelines were published for the management of oligo JIA [4]. The initial treatment consists of nonsteroidal anti- inflammatory drugs (NSAIDS) for approximately 8 weeks. Subsequently, if inflammation and pain continues or worsens, IACs, preferably triamcinolone hexacetonide $(\mathrm{TH})$ is warranted [4]. Historically, the intraarticular corticosteroid triamcinolone hexacetonide has provided longer lasting control of arthritis in patients with oligo JIA than its counterpart, triamcinolone acetonide (TA) $[5,6]$. Since 2015 , TH has not been available for use in the United States, and TA has been used instead as the alternative treatment [7]. In this study, we aim to report the response and compare the efficacy of IAC injection with TH and TA in patients with Oligo JIA.

\section{Methods}

University at Buffalo Institutional Review Board approved this retrospective chart review study. Patients who followed at the Rheumatology Department at John R. Oishei Children's Hospital of Buffalo were identified by the diagnostic codes of oligo JIA (ICD- 10 code: M08.40). The data for the retrospective chart review was collected using the Powerchart Electronic Medical Record.

\section{Subjects}

The population for this study were children with a diagnosis of oligo articular JIA according to the ILAR classification criteria (2nd revision) [1] who received IAC injection with either TH between January 2012 and June 2015 or TA between July 2015 and December 2018. As TH was no longer available after 2015, TA was used as an alternative therapy.

Inclusion criteria included: diagnosis of oligo JIA, age less than 16 years, treatment with IAC joint injection with either TH or TA, and follow up within at least 6 months after the IAC joint injection. Exclusion criteria included use of disease-modifying anti rheumatic drugs (DMARDs) and/or failure to follow up within a 6months period. No. patients who met these criteria were excluded from the study.

\section{Clinical characteristics}

The following data were recorded: age, sex, clinical presentation at onset of disease, erythrocyte sedimentation rate (ESR), c-reactive protein (CRP), antinuclear antibody (ANA), rheumatic factor (RF), human leukocyte antigen B27 (HLA-B27), anti-cyclic citrullinated peptide (anti-CCP), the type of IAC used, disease duration before presentation, time of follow-up, and the response to treatment.

\section{Procedure}

Two rheumatologists in the rheumatology department at Oishei Children's Hospital performed most IAC injections. Six joints were injected by the interventional radiology department at Oishei Children's Hospital and one joint was injected by a sports medicine provider not affiliated with our institution; the former due to the need for ultrasound guidance, and the latter due to the patient being out of state at the time of a flare up. The doses used for $\mathrm{TH}$ were $1 \mathrm{mg} / \mathrm{kg}$ for large joints (knees and hips) and $0.5 \mathrm{mg} / \mathrm{kg}$ for smaller joints (ankles, wrists, and elbows) [8]. For TA, higher dose was used, ranging from $1.2-1.7 \mathrm{mg} / \mathrm{kg}$ for large joints. All patients had a detailed musculoskeletal exam documented at baseline prior to IAC joint injection, and at any follow up visit after the IAC joint injection.

\section{Outcome}

The presence of active arthritis was determined by the presence of pain with motion, swelling, limitation in passive range of motion, or warmth. A responder is defined as a patient with at least 6 months of sustained absence of active arthritis after IAC injection. A non- responder is defined as a patient with active arthritis during their first follow up after IAC injection. The initial follow up appointment after IAC injection ranged from one to 4 months. We recorded the duration of response to treatment in the responder group. 


\section{Data analysis}

Descriptive characteristics were computed to characterize the study sample. Gender was reported as a proportion in percentage, and continuous level variables (e.g., age at onset of disease) as means and range. A chi square tests of independence was used to compare the difference in response rate between $\mathrm{TH}$ and $\mathrm{TA}$ joint injections. A chi square test also was used to compare outcome of only knee joint injection with $\mathrm{TH}$ and TA. Likewise, separate Fisher's exact tests were used to assess for differences in response rates between patients with elevated and normal CRP levels and for differences in response rates between patients with elevated and normal ESR levels. An independent t-test was used to investigate whether the duration of response to IAC joint injections differed for $\mathrm{TH}$ versus TA. Analyses were conducted assuming two-tailed hypotheses, an alpha of 0.05 , and using SYSTAT 13 (SYSTAT Software, 2004).

\section{Results}

We identified 65 patients with oligo JIA. Sixteen patients did not receive IAC joint injection due to family desire to try less invasive treatments or loss of follow up. The remaining 49 patients underwent IAC joint injections. The demographic data is summarized in Table 1. Other than four patients who were diagnosed after 24, 36, 48.and 72 months of symptom onset, patients were diagnosed within 2 months of disease onset.

One hundred nineteen IAC joint injections were performed on 49 patients. Of the 119 IAC joint injections performed, 8 were excluded. Two injected joints were excluded due to lack of follow up after injection to assess for response, 5 due to disease modifying agents (DMARDS) use at any time after IAC joint injection, and 1 for using methylprednisolone IAC joint injection

Table 1 Demographic data and type of injected joint

\begin{tabular}{|c|c|c|}
\hline \multicolumn{2}{|l|}{ Number of Patients } & 49 \\
\hline \multicolumn{2}{|l|}{ Female } & $38 / 49(78 \%)$ \\
\hline \multicolumn{2}{|l|}{ Male } & $11 / 49(22 \%)$ \\
\hline \multicolumn{2}{|c|}{ Mean age at onset of disease (years) } & 6.7 (Range 1-15) \\
\hline \multicolumn{2}{|c|}{ Mean disease duration (months) } & 7 (Range 1-72) \\
\hline Injected Joints & Number & Percent \\
\hline Knee & 78 & 70 \\
\hline Ankle & 13 & 12 \\
\hline Elbow & 4 & 3.6 \\
\hline Hip & 4 & 3.6 \\
\hline Wrist & 9 & 8.1 \\
\hline Temporomandibular & 2 & 1.8 \\
\hline Subtalar & 1 & 0.9 \\
\hline Total & 111 & \\
\hline
\end{tabular}

after initial joint injection with $\mathrm{TH}$ or TA. The remaining 111 joints that were injected included 78 knees (70.3\%), 13 ankles (11.7\%), 9 wrists (8.1\%), 4 hips (3.6\%), 4 elbows (3.6\%), 2 TMJs (1.8\%) and one subtalar. joint $(0.9 \%)$ (Table 1$)$.

Overall, 61\% (68/111) of joints responded to either $\mathrm{TH}$ or TA IAC injection. A greater percentage of joints treated with TH sustained response 73\% (38 of 52) compared with $51 \%$ (30 of 59) of joints treated with TA ( $p=$ 0.016). At the initial follow up appointment between 1 and 4 months after injection, 27\% (14/52) joints in the TH group showed active arthritis compared to 49\% (29/ 59) joints in the TA group. Within the first year after receiving a joint injection with TH or TA, 11.9\% (7/59) of joints injected with TA had to be reinjected compared to only $3.8 \%(2 / 52)$ in the TH group. To avoid bias based on the type of injected joint we compared the outcome of only knee IAC injection. We have 78 knee IAC injection. A greater percentage of knees treated with $\mathrm{TH}$ sustained response $84 \%$ (31 of 37) compared with 49\% (20 of 41) of knees treated with TA $(p=0.001)$.

Laboratory characteristics showed positive ANA in 23 patients and none with positive RF or positive antiCCP. There is a 12 years old girl and a 5 years old boy with positive HLA- B27. Of the patients with elevated CRP, 83\% (5/6) responded to IAC joint injection compared to $65 \%(15 / 23)$ of patients with normal CRP. Of the patients with elevated ESR, 88\% (14/16) responded to joint injection while $60 \%(14 / 23)$ of patients with normal ESR did not respond. Despite the magnitude of the difference in response between elevated and normal CRP and ESR levels, the results did not reach statistical significance due to the relatively small sample sizes.

When examining the duration of response after IAC joint injection, we found that the duration of response for $\mathrm{TH}$ was significantly longer ( 2.66 years) than the response duration for TA which was 1.70 years $(p=0.026)$ (Table 2).

Intra-articular steroid treatment was generally safe with only two patients exhibiting subcutaneous atrophy

Table 2 Duration of response to IAC joint injection

\begin{tabular}{lll}
\hline $\begin{array}{l}\text { Duration of } \\
\text { Response }\end{array}$ & $\begin{array}{l}\text { Response TH } \\
\text { (joints number) }\end{array}$ & $\begin{array}{l}\text { Response to TA } \\
\text { (joints number) }\end{array}$ \\
\hline 6 month & 8 & 4 \\
1 year & 10 & 11 \\
2 year & 3 & 9 \\
3 year & 2 & 4 \\
4 year & 6 & 2 \\
5 year & 6 & 0 \\
7 year & 3 & 0 \\
\hline
\end{tabular}

Total number of responded joint 68/111 (61\%) Response to TH 38/52 (73\%). Response to TA 30/59 (51\%) 
at the injection site, one from the $\mathrm{TH}$ group and one from TA. No complications such as joint infections, bleeding or chemical synovitis were reported (Table 3).

\section{Discussion}

In children with JIA, IAC can provide pain relief, improve mobility, and delay or even prevent irreversible joint destruction [9-13]. $\mathrm{TH}$ and TA are among the most common medications used for IAC in JIA patients. The efficacy of $\mathrm{TH}$ has been studied and reported in the literature with rates of remission at 6 months ranging from 63.3 to $82 \%$ [9, 14, 15]. Sample sizes were as large as 794 joint injections in some studies [16]. The efficacy of TA is reported with 6 month response rates varying from 53.4 to $100 \%$ [17-19]. It is notable that studies of TA had small sample sizes ranging from 11 to 26 patients [17-19].

TH has not been available in United States since 2015 and from our knowledge there are no studies showing response to use of TA over the last 4 years. Before 2015, there were a limited number of studies that compared TH and TA efficacy in oligo JIA [5, 6, 16, 20]. Most of these studies found $\mathrm{TH}$ to be superior to TA at both the same and increased doses with different percentages of responses $[5,6,16,20]$.

The results of our study are consistent with previous publications demonstrating the superior efficacy of $\mathrm{TH}$ over TA. In our study, after 6 months of IAC injection $73 \%$ of injected joints with $\mathrm{TH}$ group had sustained response compared to $50.8 \%$ in TA group. Twenty seven percent of joints injected with $\mathrm{TH}$ showed active arthritis 1-4 months after treatment compared to $49 \%$ of joints in the TA group showing no response. TH showed more efficacy despite using higher dose of TA in some of our patients.

Our study is unique from past research in that it examined a longer duration of follow up. Most of the previous studies showed response only at 6 months, 12 months and maximum 24 months $[5,6]$. We have patients showing response for 3-7 years after a single joint injection particularly in the $\mathrm{TH}$ group. The duration of response for $\mathrm{TH}$ was 2.658 years and for TA was 1.70 years $(p=0.026)$ showing superior effect of $\mathrm{TH}$ for a longer duration.

We analyzed different variables that may affect the efficacy of IAC joint injection including inflammatory markers and duration of disease before treatment.

Table 3 TH and TA safety

\begin{tabular}{ll}
\hline Complication & Number of joints \\
\hline Subcutaneous atrophy & 1 joint injection with TH and 1 with TA \\
Infection & 0 \\
Bleeding & 0 \\
\hline
\end{tabular}

Results did not show a statistically significant difference in the rate of sustained response for 6 months after treatment with $\mathrm{TH}$ or TA between patients with elevated or normal CRP and ESR, though we cannot rule out type two error due to the small sample size.

Literature showed mixed results, Ravelli et al. found children with high ESR were more likely to have sustained response [21] while Hertzberger-ten Cate et al. found no correlation with ESR [22]. Lanni et al. showed risk of synovitis flare was higher in patients who had elevated CRP which is not consistent with our study [23].

We found no relationship between response and duration of disease before treatment $(p=0.784)$. In the study by Allen et al. they found favorable outcome was correlated with short disease duration [15].

In terms of adverse side effects to treatment with $\mathrm{TH}$ or TA in our study, the treatments were well tolerated.

\section{Conclusion}

The results of our study are comparable to the few studies published that indicate the superiority of $\mathrm{TH}$ compared to TA in the sustained treatment of oligo JIA. Many factors may affect the efficacy of this treatment modality, however the majority of evidence on this topic is largely inconclusive, anecdotal, or conflicting, with mixed results pertaining to disease duration, ESR, and CRP. One limitation of our study is the retrospective nature and small sample size. In addition, we have 2 patients with positive HLA 27 and 2 patients with TMJ involvement that is not typical for oligo JIA. Larger prospective studies analyzing the response to TA and predictors of response including the medication dose should be considered to confirm our findings.

\section{Abbreviations \\ Oligo JIA: Oligo-articular juvenile idiopathic arthritis; IAC: Intra-articular corticosteroid; TH: Triamcinilone hexacetonide; TA: Triamcinilone acetonide; ESR: Erythrocyte Sediminatation Rate; ILAR: International League of Associations for Rheumatology; CRP: C-reactive protein; DMARDs: Disease modifying anti-rheumatic Drugs}

\section{Acknowledgements}

The authors thank Mrs. Christina Podlucky, high school teacher at Grand Island Public Schools for the considerable time taken to review the manuscript. The authors are also immensely grateful for the Linda Basta Memorial Arthritis Walk for supporting the publication fee.

\section{Authors' contributions}

RM directed the drafting, revising, and reviewing of the manuscript. RA directed the care of the patient and the drafting, revising, and reviewing of the manuscript. WJ and BA assisted in data collection and reviewed the manuscript. BW assisted in data analysis. TH directed the care of the patients and reviewed and resived the final manuscript. All authors approved the final manuscript as submitted and all are accountable for all aspects of the work presented in this manuscript.

\section{Authors' information}

Dr. Rabheh Abdul Aziz MD.MS is the principal investigator and caretaker of the patients of this project and was responsible for establishing the hypothesis as well as the general structure of the entire project. 
Dr. Rana Harhay, DO is responsible for the majority of the drafting of the manuscript and is the first author.

Dr. Brian Wrotniak, PhD, PT is a staticitian who aided in data analysis. Wajeeha Jeelani and Barbine Agbor are two research volunteers that aided in data collection.

Dr. Teresa Hennon, MD is a rheumatologist involved in the care of the patients and revision of the final versions of the manuscript.

\section{Funding}

No funding obtained.

\section{Availability of data and materials}

Upon request.

\section{Declarations}

\section{Ethics approval and consent to participate}

University at Buffalo Institutional Review Board approved this retrospective chart review study. Patients who followed at the Rheumatology Department at John R. Oishei Children's Hospital of Buffalo were identified by the diagnostic codes of oligo JIA (ICD- 10 code: M08.40).

\section{Consent for publication}

$\mathrm{N} / \mathrm{A}$; retrospective chart review.

\section{Competing interests}

None of the authors have any financial or any non-financial competing interests to declare in relation to this manuscript.

\section{Author details}

'Department of Pediatrics, University at Buffalo, Oishei Children's Hospital, Buffalo, NY, USA. ${ }^{2}$ Department of Pediatric Rheumatology, University at Buffalo, Oishei Children's Hospital, Buffalo, NY, USA. ${ }^{3}$ Department of Microbiology and Immunology, Jacobs School of Medicine and Biomedical Sciences, Buffalo, NY, USA.

Received: 30 June 2020 Accepted: 4 March 2021

Published online: 20 March 2021

\section{References}

1. Petty RE, et al. International league of associations for rheumatology classification of juvenile idiopathic arthritis: second revision, Edmonton, 2001. J Rheumatol. 2004;31(2):390.

2. Hersh $\mathrm{AO}$, Prahalad S. Immunogenetics of juvenile idiopathic arthritis: a comprehensive review. J Autoimmun. 2015;64:113-24.

3. Zuber Z. Oligoarticular onset juvenile idiopathic arthritis as the most common cause of disability of children and young adults. Reumatologia. 2019:57:198-1.

4. Beukelman T, et al. 2011 American college of rheumatology recommendations for the treatment of juvenile idiopathic arthritis: initiation and safety monitoring of therapeutic agents for the treatment of arthritis and systemic features. Arthritis Care Res (Hoboken). 2011;63(4):465-82

5. Zulian F, et al. Comparison of intra-articular triamcinolone hexacetonide and triamcinolone acetonide in oligoarticular juvenile idiopathic arthritis. Rheumatology (Oxford). 2003;42(10):1254-9

6. Zulian F, et al. Triamcinolone acetonide and hexacetonide intra-articular treatment of symmetrical joints in juvenile idiopathic arthritis: a doubleblind trial. Rheumatology (Oxford). 2004:43(10):1288-91.

7. Bingham CA, Scalzi L, Boomsma D, Groh B, Gaffney N, Sertial S, Hahn T, Lacroce V, Ostrov B. Resurrecting Triamcinolone Hexacetonide (the Steroid Formerly Known as Aristospan ${ }^{\circledR}$ ): Efficacy and Safety of a Compounded Preparation of Triamcinolone Hexacetonide for Intra-Articular Injection in Children with Arthritis [abstract]. Arthritis Rheumatol. 2018;70(suppl 10).

8. Cleary AG, Murphy HD, Davidson JE. Intra-articular corticosteroid injections in juvenile idiopathic arthritis. Arch Dis Child. 2003;88(3):192-6.

9. Breit W, et al. A subgroup-specific evaluation of the efficacy of intraarticular triamcinolone hexacetonide in juvenile chronic arthritis. J Rheumatol. 2000; 27(11):2696-702

10. Honkanen VE, Rautonen JK, Pelkonen PM. Intra-articular glucocorticoids in early juvenile chronic arthritis. Acta Paediatr. 1993;82(12):1072-4.
11. Huppertz $\mathrm{HI}$, et al. Intraarticular corticosteroids for chronic arthritis in children: efficacy and effects on cartilage and growth. J Pediatr. 1995;127(2): 317-21.

12. Rocha $\mathrm{RH}$, et al. Time effect of intra-articular injection with triamcinolone Hexacetonide and its correlations: a case-control prospective 12-month study. Am J Phys Med Rehabil. 2019;98(10):872-8.

13. Southwood TR. ABC of rheumatology. Arthritis in children. BMJ. 1995; 310(6981):728-32.

14. Padeh S, Passwell JH. Intraarticular corticosteroid injection in the management of children with chronic arthritis. Arthritis Rheum. 1998;41(7): $1210-4$

15. Allen $\mathrm{RC}$, et al. Intraarticular triamcinolone hexacetonide in the management of chronic arthritis in children. Arthritis Rheum. 1986;29(8): 997-1001.

16. Eberhard BA, llowite NT, Sison C. A dose schedule for intraarticular steroids in juvenile arthritis. J Rheumatol. 2012;39(2):374-6.

17. Yang $\mathrm{MH}$, et al. Intraarticular triamcinolone hexacetonide injection in children with chronic arthritis: a survey of clinical practice. Acta Paediatr Taiwan. 1999;40(3):182-5.

18. Unsal E, Makay B. Intraarticular triamcinolone in juvenile idiopathic arthritis. Indian Pediatr. 2008;45(12):995-7

19. Verma $\mathrm{S}$, et al. Feasibility and efficacy of intraarticular steroids (IAS) in juvenile idiopathic arthritis (JIA). Indian Pediatr. 2009;46(3):264-5.

20. Eberhard BA et al. Comparison of the intraarticular effectiveness of triamcinolone hexacetonide and triamcinolone acetonide in treatment of juvenile rheumatoid arthritis. J Rheumatol. 2004;31(12):2507-12.

21. Ravelli $A$, et al. Factors affecting the efficacy of intraarticular corticosteroid injection of knees in juvenile idiopathic arthritis. J Rheumatol. 2001;28(9): 2100-2.

22. Hertzberger-ten Cate $\mathrm{R}$, et al. Intra-articular steroids in pauciarticular juvenile chronic arthritis, type 1. Eur J Pediatr. 1991;150(3):170-2.

23. Lanni $\mathrm{S}$, et al. Outcome and predicting factors of single and multiple intraarticular corticosteroid injections in children with juvenile idiopathic arthritis. Rheumatology (Oxford). 2011;50(9):1627-34.

\section{Publisher's Note}

Springer Nature remains neutral with regard to jurisdictional claims in published maps and institutional affiliations.

\section{Ready to submit your research? Choose BMC and benefit from:}

- fast, convenient online submission

- thorough peer review by experienced researchers in your field

- rapid publication on acceptance

- support for research data, including large and complex data types

- gold Open Access which fosters wider collaboration and increased citations

- maximum visibility for your research: over $100 \mathrm{M}$ website views per year

At $\mathrm{BMC}$, research is always in progress.

Learn more biomedcentral.com/submissions 